\title{
ORIGINAL ARTICLE \\ Education of Cognitive of Emotion Regulation on Athletic Performance of High School Male Students
}

\author{
${ }^{1}$ MIR HAMID SALEHIAN, ${ }^{2}$ RECEP GURSOY, ${ }^{2}$ TAYEBEH BANI ASADI, ${ }^{3}$ PARINAZ GHANATI \\ ${ }^{1}$ Department of Physical Education, Tabriz Branch, Islamic Azad University, Tabriz, Iran \\ ${ }^{2}$ Faculty of Sport Sciences, Muğla Sıtkı Koçman University, Muğla, Turkey \\ ${ }^{3}$ Department of Kinesiology, Indiana University Bloomington, USA. \\ ${ }^{4}$ Department of Motor behavior, University of Tehran, Iran, Email: m_salehian@iaut.ac.ir
}

\begin{abstract}
The main purpose of this research was to study the effect of emotional regulation on the athletic performance. The present research was descriptive-correlational in terms of research method and applied in terms of purpose and survey in terms of data collection method, which was conducted in the field. The statistical population of this study includes all male athletes in Bayburt in team (football, volleyball and handball) and individual (track and field, judo), with an average age of $16 \pm 2.6$ years old, from which 30 students were randomly selected Voluntarily. Data collection tools consisted of three questionnaires: Charbonneau exercise performance questionnaire (2001) and emotional cognitive regulation questionnaire (Garnowski et al., 2001). The validity of these two questionnaires was 0.82 and 0.91 by Cronbach's alpha coefficient in this study. Regression correlation test was used to test the hypotheses. The results showed that the athletic performance of high school male students can be affected by cognitive emotion regulation. By training the emotions of high school male students their performance get better and cope with the challenges.
\end{abstract}

Keywords: Emotion regulation, high school students, male

\section{INTRODUCTION}

One of the basic variables in the field of sports performance is cognitive emotion regulation. ${ }^{1}$ Cognitiveemotional regulation is the strategies that people use in distressed situations to control their emotions. ${ }^{2}$ Although emotions have a biological basis, individuals are able to control emotions and their tools. ${ }^{3}$ When a person is faced with a situation, feeling good and optimistic is not enough to control his emotions alone, he needs to have the best cognitive function in these moments. ${ }^{2}$ According to several theories of emotion, it can play a constructive role in and increase ${ }^{4}$ the decision-making process. ${ }^{4}$

Garnefski et al. ${ }^{1}$ also showed in their studies that the general population suffering from depression uses negative cognitive regulation strategies such as rumination in a dream with unfortunate conditions. In summary, it can be concluded that the type of cognitive strategy of emotion is a factor affecting the level of mental health They believed that any violation of emotion regulation can make a person vulnerable to psychological problems such as depression and anxiety. Mental health is the result of two-way interaction between the use of certain types of cognitive emotion regulation strategies and the correct assessment of a stressful situation. ${ }^{1}$

Research has been formed and conducted on this basis, mainly considering the basic psychological needs as an independent variable or a default variable, and the results of many studies, including Fathi et al., ${ }^{5}$ have shown that the basic psychological needs of Individual performance is affected, including the degree of adaptation, but no research has been observed to show which variables can predict the provision of basic psychological needs.

With the study and studies done on the athletic performance of professional athletes, it was concluded that so far no significant study has been done on the cognitive regulation of these athletes. Therefore, considering the importance of the above-mentioned issues, a thorough study of those cases was considered very important, because the results of this study can help activists in the field of sports psychology in how to deal properly and logically with professional athletes. Using the results of this research, the necessary and appropriate solutions can be provided to officials, coaches, athletes and parents to use them with appropriate emotional regulation to increase the performance of athletes.

Research methodology: The present study is a descriptive correlational study in terms of method and applied in terms of purpose and a survey in terms of data collection method, which was conducted in the field. The statistical population of this study included female semiprofessional athletes in Tabriz in team (football, volleyball, handball) and individual (track and field, judo) with professional skill level, with an average age of $16 \pm 22.6$ from three sports. The statistical sample of this study was 100 high school male students who were voluntarily selected as a sample and were randomly divided into two groups of 50 emotional training and control group and were trained in emotional regulation.

\section{Research tools}

Charbonneau Sports Performance Questionnaire: ${ }^{6}$ This questionnaire was developed in 2001 by Charbonneau. The questionnaire has five questions on the Likert scale and is designed to evaluate the performance of athletes and is completed by the relevant coach of each athlete. The scores obtained from the five questions show the final scores of the athlete's performance. This question is designed on a scale of 1 (very poor) to 5 (excellent). The scores obtained from the five questions are added together and the final score of the athlete's performance is obtained. This final score of the athlete's performance ranges from 5 to 25 (at least up to Maximum). The average reliability coefficients of this questionnaire were calculated and reported by Charbonio 0.71 . In this study, the validity of the questionnaire was confirmed by five physical education 
professors in the province and its reliability was $68.5 \%$ through Cronbach's alpha.

The Cognitive Emotion Regulation Questionnaire: ${ }^{6}$ It has as 36 items. The scores of it is in the form of a fivepoint Likert scale (1-almost never to 5-almost always). The questionnaire consists of 36 five-point graded questions that assess all four questions of a factor, and a total of nine factors to blame, self-blame, blame others, catastrophic, rumination, concentration Re-evaluates admission planning, positive focus, and positive evaluation. Cronbach's alpha method was used to determine the reliability of the questionnaire. The coefficients obtained for the questionnaire $(\alpha=0.81)$ were obtained. In this study, the validity of the questionnaire was confirmed by five physical education professors in the province and its reliability was obtained through Cronbach's alpha for the subscale of selfblame 0.79 , rumination 0.91 , catastrophic 0.78 and another 0.89.

Data collection method: After studying and collecting the principles related to emotion regulation and preparing the relevant questionnaires for the statistical population, the researcher proceeded. 100 male students from team (football, volleyball and handball) and individual (track and field, judo) were selected voluntarily. After completing the questionnaires, they were divided into experimental and control groups. After the trainings, the questionnaires were redistributed and collected for 10 sessions. After collecting the questionnaires, the raw information was coded and the data were analyzed.

Statistical analysis methods: Multivariate linear regression analysis was used to investigate the effect of emotion regulation training on athletic performance of male students.

\section{RESULTS}

Table 1. Significance test of linear relationship for the effect of cognitive emotion regulation on athletic performance

Table 1. Effect of cognitive regulation on performance

\begin{tabular}{|l|l|l|l|l|l|}
\hline Variable & Total squares & $\mathrm{df}$ & $\begin{array}{l}\text { Mean } \\
\text { squares }\end{array}$ & $\mathrm{F}$ & Sig. \\
\hline \multirow{2}{*}{$\begin{array}{l}\text { Cognitive } \\
\text { regulation }\end{array}$} & regression & 1 & 12.538 & 28.342 & \multirow{2}{*}{0.001} \\
\cline { 2 - 5 } & Remaining & 98 & 0.42 & & \\
\cline { 2 - 5 } & & 99 & & & \\
\hline
\end{tabular}

As Table 1 shows, cognitive emotion regulation training has a significant positive effect on athletic performance.

\section{DISCUSSION AND CONCLUSION}

Findings showed that athletic performance of high school male students improves with cognitive emotion regulation training. The results of this study are consistent with the results of Maghsoudi et al., ${ }^{7}$ Salehian, Ghadiri, ${ }^{6}$ Salehian et al. $^{8}$ and are inconsistent with the findings of Sahebi et al. ${ }^{9}$ Sahebi et al. ${ }^{10}$ by studying the effect of external focus and cognitive emotion regulation strategies on the performance of the ancient wheel and grass, the researchers concluded that the adoption of adaptive and non-adaptive cognitive emotion regulation strategies had no effect on their performance. Individual characteristics (adaptive strategies and non-adaptive emotion regulation strategies) probably did not have a significant effect on their performance. ${ }^{11,12}$

In explaining this issue, it can be stated that the mental and emotional state of athletes is one of the important and influential factors on their performance. Emotion plays a fundamental role in mental disorders. Emotional imbalances occur in all Axis One disorders (except mental retardation) and half of Axis Two disorders (childhood disorders, personality disorders, and mental retardation). ${ }^{11}$ On the other hand, successful emotion regulation is accompanied by positive achievements, such as the development of social competencies. ${ }^{12}$

Emotional responses provide important information about one's experience with others. From this information, human beings learn how to deal with emotions, how to express emotional experiences verbally, what strategies to use in response to emotions, and how to treat others in the context of specific emotions. A review of psychological studies shows that emotional regulation is an important factor in determining health and having a successful performance in social interactions. Therefore, it can have a positive effect on a person's performance in some way. ${ }^{13}$ According to the research results, it is suggested that sports officials hold training courses and workshops on psychological issues and emotional regulation.

\section{REFERENCES}

1. Garnefski N, Kraaij V, \& Spinhoven P, (2017). Negative life events, cognitive emotion regulation, and emotional problems, Personality and Individual Differences, 30 (8): 1311-1327.

2. Gross, J. J. \& John. O. P. (2003). The relationship between cognitive emotion regulation strategies and emotional problems: comparison between a clinical and a non-clinical sample, European journal of personality, 16 (5), $403-420$.

3. Van Dillen, L.F., \& kool, S.L. (2007). Clearing the mind a working memory odel of distraction from negative emotion, Journal pf personality. 7: 715-723.

4. Isen, A. M., Rozenzweig, A. S. (1994). The influence of positive affect on clinical problem solving, Medical Decision making, 11, 221-227.

5. Fathi, A., Rezapour, Y., \& Yaghootiazar, S. (2010). Determining the relationship between basic needs and social support with social adjustment in male and female students. Social Security Studies Quarterly. 131-146.

6. Salehian, M.H., Ghadiri, S. (2018). Anticipation of Emotion Regulation and Psychological Well-being on Athletic Performance of Professional and Semi-professional Athletes, Sport Psychology Studies, 8 (29), 151-17.

7. Maghsoudi, F., Ajilchi, B., Zareian, E. (2018). The Relationship between Cognitive Emotion Regulation and Coping Styles with Athletic Success of Athlete Students, Sport Psychology, Shahid Beheshti University, 3 (1): 36-23. (Persian)

8. Salehian, MH., Pour Haji, S., Harzandi, H., Ghanati, P. (2021). The Effect of Cognitive Emotion Regulation on Athletic Performance of Semi-professional Athletes, The Seconal national conference on sport sciences, Urmai, Iran.

9. Sahebi, A., Shahabi Kaseb, M. R,, ZeidAbadi, P. (2017). The effect of external focus and cognitive emotion regulation strategies on the performance of archaeologists' sharp wheel and turf, Sports Psychology Studies, 19, 42-31. (Persian)

10. Sahebi, A., Shahabi Kaseb, M. R,, ZeidAbadi, P. (2017). The effect of external focus and cognitive emotion regulation strategies on the performance of archaeologists' sharp wheel and turf, Sports Psychology Studies, 19, 42-31. (Persian)

11. Aldao, A., Nolen-Hoeksema, S. \& Schweizer, S. (2010). Emotion-Regulation Strategies across Psychopathology: A MetaAnalytic Review, Clinical Psychology Review, 30(2): 217-237.

12. Eisenberg, N., Fabes, R. A, Guthrie, I. K., \& Reiser, M. (2000). Dispositional emotionality and regulation: Their role in predicting quality of social functioning, Journal of personality and social psychology, 78: 138-157.

13. BaniAsadi, T., Salehian, M.H. (2021). The Effect of Psychological Well-being on Athletic Performance of Professional Athletes, 15(5), 1680-1683 